\title{
EFEITO DO CONTROLE ESTRATÉGICO DE Amblyomma cajennense (FABRICIUS, 1787) (ACARI: IXODIDAE) SOBRE A POPULAÇÃO DE Anocentor nitens (NEUMANN, 1897) (ACARI: IXODIDAE) EM EQÜINOS*
}

\author{
ARILDO P. DA CUNHA ${ }^{1}$; ANA CRISTINA P. DE PAIVA BELLO ${ }^{1}$; ROMÁRIO C. LEITE ${ }^{2}$; ANTÔNIO CÂNDIDO \\ C. LEITE RIBEIRO ${ }^{3}$; CAROLINA MARIA V. DE FREITAS $^{4}$; EDUARDO BASTIANETTO'; ${ }^{1}$ PAULO R. OLIVEIRA ${ }^{2}$
}

\begin{abstract}
CUNHA, A.P. DA; BELLO, A.C.P. DE P.; LEITE, R.C.; RIBEIRO, A.C.C.L.; FREITAS, C.M.V. DE; BASTIANETTO, E.; OLIVEIRA, P.R. Effect of the strategic control of Amblyomma cajennense (Fabricius, 1787) (Acari: Ixodidae) on the population of Anocentor nitens (Neumann, 1897) (Acari: Ixodidae) in equines.] Efeito do controle estratégico de Amblyomma cajennense (Fabricius, 1787) (Acari: Ixodidae) sobre a população de Anocentor nitens (Neumann, 1897) (Acari: Ixodidae) em eqüinos. Revista Brasileira de Parasitologia Veterinária, v. 16, n. 4, p. 215-219, 2007. Departamento de Medicina Veterinária Preventiva, Escola de Veterinária, Universidade Federal de Minas Gerais, Av. Antônio Carlos, 6627, São Francisco, Belo Horizonte, MG 31270-010, Brasil. E-mail: rcleite@vet.ufmg.br

The objective of this study was to evaluate the effect of the Amblyomma cajennense strategic control program on the Anocentor nitens population. The acaricide treatments were carried out every seven days and divided in two series, the first one beginning in April 2004 (eight treatments) and the second beginning in July of the same year (five treatments), using pyrethroid chemical base - cypermethrin in the concentration of 0,015\%. Monthly it was evaluated the infestation of $A$. nitens in the ear and nasal diverticulum of the equines before (October 2003 to March 2004) and after (October of 2004 to March of 2005) the strategic program of acaricide treatments. It was used score of 0 to 3 to classify the infestation levels. It did not have any significant reduction of the parasitic load of A. nitens in the ear and nasal diverticulum of the equines. Possibly, due to absence of acaricide in the nasal diverticulum. Therefore, this anatomical structure it is an important place of infestation by A. nitens in equines.
\end{abstract}

KEY WORDS: Equines, Anocentor nitens, nasal diverticulum, control.

\section{RESUMO}

Objetivou-se avaliar o efeito de um programa de controle estratégico de Amblyomma cajennense sobre a população de Anocentor nitens em eqüinos. Os tratamentos carrapaticidas foram realizados a cada sete dias e divididos em dois módulos, o primeiro com início em abril de 2004 (oito tratamentos) e o segundo com início em julho do mesmo ano (cinco tratamentos), utilizando-se a base química piretróide - cipermetrina na concentração de $0,015 \%$. Avaliou-se mensalmente a carga parasitária de $A$. nitens no pavilhão auricular e divertículo nasal

\footnotetext{
* Sob os auspícios do CNPq (Processo número 479731/2004-7).

${ }^{1}$ Curso de Pós-Graduação em Ciência Animal, Escola de Veterinária, Universidade Federal de Minas Gerais (UFMG).

${ }^{2}$ Departamento de Medicina Veterinária Preventiva, Escola de Veterinária, UFMG, Av. Antônio Carlos, 6627, São Francisco, Belo Horizonte, MG 31270-010, Brasil. E-mail: rcleite@vet.ufmg.br

${ }^{3}$ EMBRAPA Gado de Leite.

${ }^{4}$ Universidade Presidente Antônio Carlos (UNIPAC).
}

dos eqüinos antes (outubro de 2003 a março de 2004) e depois (outubro de 2004 a março de 2005) do controle estratégico com banhos carrapaticidas. Utilizaram-se escores de 0 a 3 para classificar os níveis de infestação. Entretanto, não houve redução significativa da carga parasitária de A. nitens no pavilhão auricular e no divertículo nasal dos eqüinos, possivelmente, devido a não aplicação sistemática de carrapaticida no divertículo nasal, pois, esta estrutura anatômica é um importante sítio de infestação por $A$. nitens em eqüinos.

PALAVRAS-CHAVE: Eqüinos, Anocentor nitens, divertículo nasal, controle.

\section{INTRODUÇÃO}

O carrapato Anocentor nitens (Neumann, 1897) é considerado, no Brasil, uma das principais espécies de carrapatos dos eqüídeos (BORGES; LEITE, 1993a). Conhecido como "carrapato da orelha do cavalo" (FLECHTMANN, 1977), determina inúmeros prejuízos pela queda na produtividade dos 
animais, irritação, espoliação sangüínea, predisposição a miíases e infecções bacterianas secundárias e queda do pavilhão auricular (MALHEIRO, 1952; BORGES; LEITE, 1998). Além disso, A. nitens é vetor da Babesia caballi (Nutall; Strickland), agente etiológico da babesiose eqüina (ROBY; ANTHONY, 1963).

Os conhecimentos de biologia e epidemiologia dos parasitos são de fundamental importância nas intervenções de controle (LEITE et al., 1997). Podem-se destacar os estudos realizados por Daemon e Serra-Freire (1984) e por Borges e Leite (1993a) que caracterizaram o comportamento biológico de A. nitens na fase não parasitária em condições de laboratório. A dinâmica sazonal deste carrapato como parasito de eqüinos foi observada por Souza e Serra-Freire (1992) em Itaguaí, RJ, por Borges et al. (2000) em Pedro Leopoldo, MG, e por Labruna et al. (2002) em Pirassununga, SP. A dinâmica sazonal da fase não parasitária foi estudada por Souza e SerraFreire (1994) e Borges et al. (1999).

Anocentor nitens é um carrapato monoxeno (LABRUNA et al. (2002) e que realiza diferentes gerações por ano na Região Sudeste do Brasil (SOUZA; SERRA-FREIRE, 1992; SOUZA; SERRA-FREIRE, 1994; BORGES et al., 1999; BORGES et. al., 2000). Sanavria e Prata (1996) estudaram a fase parasitária de $A$. nitens em eqüinos, observando períodos larval e ninfal de oito e dez dias, respectivamente; com a queda da maioria das fêmeas ocorrendo 28 dias após a inoculação das larvas, estimando-se em 63 dias o tempo necessário para se completar o ciclo biológico em condições de laboratório. Enquanto que Freitas et al (1984) observaram a permanência de machos de $A$. nitens por até 100 dias após a inoculação das larvas.

De acordo com Falce (1986) e Borges et al. (2000) A. nitens têm predileção em infestar a face interna da orelha dos eqüídeos, podendo infestar outros sítios como o períneo, a cauda e a região da virilha (Labruna et al., 2002), e também, o divertículo nasal (BORGES; LEITE, 1993a).

São poucas as informações existentes a respeito do controle de $A$. nitens em eqüinos. Na maioria das vezes, utilizamse dos artifícios disponíveis para o controle de Boophilus microplus em bovinos. Visando a operacionalidade do controle integrado de carrapatos em eqüinos, objetivou-se com este estudo avaliar o efeito de um programa de controle estratégico de Amblyomma cajennense sobre a população de $A$. nitens em eqüinos.

\section{MATERIAL E MÉTODOS}

Este estudo foi realizado no município de Palma, região da Zona da Mata do estado de Minas Gerais, no período de outubro de 2003 a março de 2005. Foram utilizados 16 eqüinos adultos (11 machos e 5 fêmeas) sem raça definida (SRD), mantidos em regime extensivo com suplementação mineral, sendo que estes permaneceram nos mesmos pastos que os bovinos. Os animais eram destinados ao trabalho, no manejo de uma propriedade de bovinocultura de leite. A partir de ou- tubro de 2003 foi implantado um esquema para o controle de helmintos, utilizando-se medicamento ${ }^{5}$ por via oral a cada três meses. A propriedade apresentava histórico de infestação natural por A. cajennense e A. nitens, porém, não empregava nenhum esquema específico para o controle de carrapatos nos eqüinos.

O programa de controle estratégico de A. cajennense foi dividido em dois módulos de tratamentos carrapaticidas nos eqüinos, utilizando-se um produto piretróide (cipermetrina ${ }^{6}$ a 0,015\%). O primeiro módulo teve início na primeira semana do mês de abril de 2004 e foi composto por oito banhos, sendo que o intervalo entre cada banho foi de sete dias. O segundo módulo teve início na primeira semana de julho e foi composto por cinco banhos, também a intervalos semanais. O intervalo entre o final do primeiro módulo e o início do segundo foi de 42 dias. Além disso, mensalmente, sempre que se constatou a presença de carrapatos no pavilhão auricular dos eqüinos, aplicou-se carrapaticida tópico ${ }^{7}$.

A estrutura para contenção dos animais e aplicação dos tratamentos carrapaticidas constitui-se de um tronco de cordoalha de aço com capacidade para cinco eqüinos, uma bomba elétrica, uma caixa d’água de 500 litros, tubulação hidráulica e um aspersor com bico transversal em cada lateral do tronco, possibilitando a operação do sistema por duas pessoas simultaneamente, conforme Leite (2004). Os animais foram banhados por completo, inclusive no pavilhão auricular. No entanto, o divertículo nasal dos eqüinos não foi acessado com a emulsão carrapaticida, pela condição anatômica e fisiológica.

A partir de outubro de 2003 a março de 2004, realizaramse mensalmente avaliações qualitativas das infestações por $A$. nitens no pavilhão auricular e no divertículo nasal do antímero esquerdo de cada eqüino. Utilizou-se a mesma metodologia no período de outubro de 2004 a março de 2005, a fim de se comparar o efeito dos tratamentos carrapaticidas. A classificação dos níveis de infestação de $A$. nitens no pavilhão auricular e divertículo nasal foi realizada aplicando os seguintes escores: 0 - para a ausência de carrapatos, 1 - para colônias com até dois centímetros de diâmetro de área infestada, 2 para colônias com diâmetro entre dois e quatro centímetros e 3 - para colônias com diâmetro acima de quatro centímetros. Quando da presença de mais de uma colônia, somaram-se as áreas das superfícies infestadas.

Os resultados foram analisados pelo teste Wilcoxon para diferenças entre pares ordenadas, segundo Sampaio (2002).

\section{RESULTADOS}

Os resultados das avaliações das cargas parasitárias de $A$. nitens realizadas nos eqüinos antes e depois do programa de controle estratégico de $A$. cajennense estão representados na Figura 1. No período de outubro de 2004 a março de 2005

\footnotetext{
${ }^{5}$ Valbazen $^{\circledR} 10$ Cobalto - Pfizer.

${ }^{6}$ Ec-Tox CE $15 \%{ }^{\circledR}$ - Schering-Ploug Saúde Animal.

${ }^{7}$ Tanidil $^{\circledR}$ - Bayer S.A.
} 


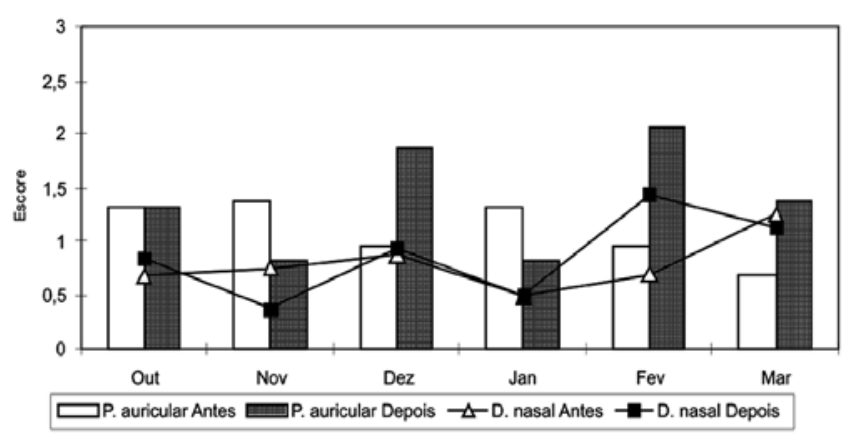

Figura 1. Valores médios dos escores de carga parasitária de Anocentor nitens no pavilhão auricular e divertículo nasal de eqüinos adultos (11 machos e 5 fêmeas) no período de outubro de 2003 a março de 2004 e de outubro de 2004 a março de 2005, Palma, MG.

Tabela 1. Percentual de eqüinos parasitados por Anocentor nitens no pavilhão auricular e divertículo nasal em avaliações realizadas antes (outubro de 2003 a março de 2004) e depois (outubro de 2004 a março de 2005) do programa de controle estratégico de Amblyomma cajennense, Palma, MG

\begin{tabular}{lccccc}
\hline \multirow{2}{*}{ Meses } & \multicolumn{3}{c}{ Presença eqüinos parasitados } \\
\cline { 2 - 3 } \cline { 5 - 6 } \cline { 5 - 6 } & \multicolumn{2}{c}{ Pavilhão auricular } & \multicolumn{2}{c}{ Divertículo nasal } \\
\cline { 2 - 3 } \cline { 5 - 6 } & Antes (\%) & Depois (\%) & & Antes (\%) & Depois (\%) \\
\hline Outubro & 50,00 & 50,00 & & 31,25 & 31,25 \\
Novembro & 56,25 & 37,50 & & 31,25 & 18,75 \\
Dezembro & 100,00 & 100,00 & & 75,00 & 62,50 \\
Janeiro & 68,75 & 50,00 & & 50,00 & 12,50 \\
Fevereiro & 56,25 & 100,00 & & 31,25 & 56,25 \\
Março & 50,00 & 81,25 & 43,75 & 68,75 \\
\hline
\end{tabular}

não houve redução da carga parasitária de $A$. nitens nos pavilhões auriculares e divertículos nasais dos eqüinos em relação ao mesmo período do ano anterior $(\mathrm{P}>0,05)$. Observouse um aumento dos índices parasitários nos meses de dezembro de 2004 e fevereiro de 2005, em relação aos correspondentes períodos dos anos anteriores, para a população de $A$. nitens dos pavilhões auriculares $(\mathrm{P}<0,05)$; o que, da mesma forma, ocorreu no mês de fevereiro de 2005 para a população dos divertículos nasais.

Na Tabela 1 estão representados os percentuais de eqüinos parasitados por A. nitens no pavilhão auricular e divertículo nasal, nas avaliações realizadas antes e depois do programa de controle estratégico de $A$. cajennense.

\section{DISCUSSÃO}

O programa de controle estratégico de $A$. cajennense não proporcionou reduções significativas nas populações de $A$. nitens dos pavilhões auriculares e divertículos nasais dos eqüinos. Pôde-se observar, em determinadas avaliações, o aumento significativo da carga parasitária após os tratamentos carrapaticidas $(\mathrm{P}<0,05)$ (Figura 1$)$.

Souza e Serra-Freire (1992) observaram a influência de tratamentos carrapaticidas sobre as curvas de carga parasitária de A. nitens, quando realizaram contagens de 12 a 14 dias após os banhos; no entanto, em determinados momentos do estudo, verificou-se o aumento do número de fêmeas semiingurgitadas e/ou ingurgitadas nos eqüinos mesmo no período de realização dos banhos. Borges et al. (2000) sugeriram que medidas de controles estratégicos para o A. nitens em eqüinos deveriam ser similares àquelas aplicadas para o controle do B. microplus em bovinos, tal como Oliveira (1993). De forma que os tratamentos carrapaticidas deveriam ser mais intensivos na primavera e verão, quando as infestações são altas, existe abundância de larvas e, o ciclo de vida do A. nitens é mais curto devido às altas temperaturas (BORGES et al., 2000).

Souza e Serra-Freire (1992), em Itaguaí, no estado do Rio de Janeiro, verificaram uma variação populacional de teleóginas de $A$. nitens, apresentando picos bimensais, com o maior pico ocorrendo no mês de maio, em dois anos consecutivos de observações. Labruna et al. (2002), em Pirassununga, estado de São Paulo, verificaram os maiores picos de infestações por teleóginas em abril, julho e outubro.

Borges et al. (2000), em Pedro Leopoldo, Minas Gerais, verificaram picos parasitários ocorrendo nos meses de novembro, janeiro e julho no primeiro ano de estudo e, em outubro, dezembro e julho no segundo ano, sendo os maiores picos registrados nos meses de julho de cada ano. No presente estudo os banhos foram realizados nos meses de abril, maio e julho, com intervalos de sete dias, isto é, período em que seria esperado atingir picos de $A$. nitens infestando os eqüinos, porém como já foi dito, não houve redução da carga parasitária. Além disso, não houve indícios de resistência do $A$. nitens ao carrapaticida utilizado, pela observação de mortalidade e queda dos carrapatos. Deduzindo-se que outras variáveis possam ter interferido nestes resultados, tal como: a não aplicação de carrapaticida no divertículo nasal.

No presente estudo, os eqüinos compartilhavam as pastagens com os bovinos, hábito que segundo Falce (1986) constitui um fator de veiculação recíproca de carrapatos, complicando o estabelecimento de medidas profiláticas a serem desenvolvidas nos rebanhos. No entanto, a propriedade empregava ações específicas para o controle do B. microplus nos bovinos.

Deve-se ressaltar que não foram realizados tratamentos carrapaticidas nos divertículos nasais dos animais, devido às dificuldades de se acessar esta região anatômica com o bico aspersor, e também, pelo desconforto e repulsa que esta operação provoca nos animais. Isto pode ter contribuído para a manutenção da carga parasitária no período de outubro de 2004 a março de 2005. Outro fator importante constatado no presente estudo foi o total desconhecimento, por parte dos funcionários da propriedade, das infestações por $A$. nitens nos divertículos nasais dos eqüinos. De acordo com Borges e Leite (1993b), os divertículos nasais são freqüentemente esquecidos como sítios de fixação de $A$. nitens e, a não ser que se esteja atento a este fato, é impossível detectar os carrapatos ali presentes.

Os eqüinos, além dos banhos carrapaticidas de outono e inverno, receberam também tratamentos tópicos mensais no 
interior do pavilhão auricular, sempre que notada a presença de carrapatos neste sítio. Porém, a carga parasitária se manteve intensa e freqüente no pavilhão auricular e divertículo nasal dos eqüinos (Figura 1 e Tabela 1), podendo ter ocorrido que os carrapatos presentes nos divertículos nasais tenham contribuído para a permanência destes níveis de infestações, por terem podido realizar completamente seu ciclo sem a influência dos tratamentos aplicados.

Labruna et al. (2001) constataram que o uso tópico de carrapaticidas nos pavilhões auriculares dos eqüinos apresentou alta associação com a presença de altas infestações de $A$. nitens, sem que, no entanto, houvesse um controle efetivo deste carrapato. Os autores verificaram também que em propriedades que realizavam tratamentos carrapaticidas tópicos nos pavilhões auriculares de todos os eqüinos, em intervalos menores que 21 dias, e sem que houvesse evidências de resistência a estes carrapaticidas, as infestações continuavam ocorrendo, demonstrando que tais carrapatos poderiam estar se alimentando em outras partes do corpo dos eqüinos que não haviam sido tratadas com carrapaticida, tais como a virilha, o períneo, a cauda e os divertículos nasais. Discutiram que medidas de controle eficiente do $A$. nitens não devem basear-se apenas nos tratamentos carrapaticidas tópicos nos pavilhões auriculares, devendo-se esquematizar um programa de banhos no corpo dos eqüinos, inclusive no divertículo nasal, em intervalos não maiores que 21 dias.

Pôde-se observar (Tabela 1) que, em determinados momentos do estudo, antes e depois dos banhos carrapaticidas, $100 \%$ dos eqüinos apresentavam infestações por $A$. nitens no pavilhão auricular; enquanto que no divertículo nasal as maiores percentuais de animais parasitados foram 75\% no mês de dezembro (antes dos banhos) e 68,75 \% no mês de março (depois dos banhos). Foi observado, em todas as avaliações, sempre um maior número de animais parasitados por $A$. nitens no pavilhão auricular em relação ao divertículo nasal; entretanto, observaram-se em diversos animais e em diferentes momentos infestações no divertículo nasal sem que houvesse carrapatos desta espécie no pavilhão auricular. Segundo Borges e Leite (1993c) o parasitismo do divertículo nasal por A. nitens independe do nível de infestação auricular. Borges et al. (2000) estudando infestações naturais de $A$. nitens em eqüinos em Minas Gerais, verificaram a ocorrência de $61 \%$ de fêmeas adultas no pavilhão auricular e 39\% em outras partes do corpo, porém este estudo não quantificou os exemplares de $A$. nitens dos divertículos nasais.

Encontram-se disponíveis na literatura estudos de biologia e epidemiologia de $A$. nitens, porém, ainda existe a demanda por informações quanto ao controle específico deste carrapato. Além disso, não existe nenhum produto comercial para o controle de $A$. nitens no divertículo nasal de eqüinos. Esta região do corpo dos eqüinos apresenta particularidades quanto ao acesso, às condições de temperatura, umidade e gases do processo respiratório e, ainda, a presença secreções oriundas das vias aéreas e do ducto nasolacrimal, fatores que devem ser considerados em programas de controle.
Agradecimentos: Este trabalho teve o apoio logístico e operacional da fazenda Rancho Agropecuária e sua equipe.

\section{REFERÊNCIAS BIBLIOGRÁFICAS}

BORGES, L.M.F.; LEITE, R.C. Aspectos biológicos do Dermacentor nitens (Neumann, 1897) em condições de laboratório. Arquivo Brasileiro de Medicina Veterinária e Zootecnia, v.45, n.6, p.586-591, 1993a.

BORGES, L.M.F.; LEITE, R.C. Teste “in vitro" de sensibilidades a acaricidas em fêmeas ingurgitadas de Dermacentor nitens (Neumann, 1897) oriundas de eqüinos de Minas Gerais e Bahia. Arquivo Brasileiro de Medicina Veterinária e Zootecnia, v.45, n.6, p.593-598, 1993 b.

BORGES, L.M.F.; LEITE, R.C. Comparação entre as populações auriculares e nasais de Dermacentor nitens (Neumann, 1897) oriundas de eqüinos de Minas Gerais e Bahia, Brasil. Revista Brasileira de Parasitologia Veterinária, v.2, n.2, p.109-110, 1993c.

BORGES, L.M.F.; LEITE, R.C. Fauna Ixodológica do pavilhão auricular de eqüinos em municípios de Minas Gerais e da Bahia. Arquivo Brasileiro de Medicina Veterinária e Zootecnia, v.50, n.1, p.87-89, 1998.

BORGES, L.M.F.; OLIVEIRA, P.R.; RIBEIRO, M.F.B. Seasonal dynamics of the free-living phase of Anocentor nitens at Pedro Leopoldo, Minas Gerais, Brazil. Veterinary Parasitology, v.87, n.1, p.73-81, 1999.

BORGES, L.M.F.; OLIVEIRA, P.R.; RIBEIRO, M.F.B. Seasonal dynamics of Anocentor nitens on horses in Brazil. Veterinary Parasitology, v.89, n.1, p.165-171, 2000.

DAEMON, E; SERRA-FREIRE, N.M. Biologia de Anocentor nitens Neumann, 1897: fase não parasitária em condições de laboratório, Revista Brasileira de Medicina Veterinária, v.6, n.6, p.181-183, 1984.

FALCE, H. C. Infestações múltiplas por ixodídeos (Acari: Ixodidae) em bovinos e eqüídeos no primeiro planalto do Estado do Paraná. Revista do Setor de Ciências Agrárias, v.5, n.1-2, p.11-13, 1986.

FLECHTMANN, C.H.W. Ácaros de importância médico veterinária. 2.ed., São Paulo: Nobel, 1977. 192p.

FREITAS, M.G.; COSTA, H.M.A.; COSTA, J.O.; IIDE, P. Entomologia e acarologia médica e veterinária. 6.ed., Belo Horizonte: Precisa, 1984. 251p.

LABRUNA, M.B.; KERBER, C.E.; FERREIRA, F.; FACCINI, J.L.H.; DE WAAL, D.T.; GENNARI, S.M. Risk factors to tick infestations and their occurrence on horses in the state of São Paulo, Brasil.Veterinary Parasitology, v.97, n.1, p.1-14, 2001.

LABRUNA, M.B.; KASAI, N.; FERREIRA, F.; FACCINI, J.LH.; GENNARI, S.M. Seasonal dynamics of ticks (Acari: Ixodidae) on horses in the state of São Paulo, Brazil. Veterinary Parasitology, v.105, n.1, p.65-77, 2002.

LEITE, R.C.; OLIVEIRA, P.R.; LOPES, C.M.L.; FREITAS, C.M.V. Alguns aspectos epidemiológicos das infestações por Amblyomma cajennense: uma proposta de controle 
estratégico. In: SIMPÓSIO SOBRE CONTROLE DE PARASITOS, 2., 1997, Colina. Anais... Campinas: CGE, 1997. p.9-14.

LEITE, R.C. Práticas auxiliares no manejo parasitário em bovinos. Merial - Coleção Gado de Corte, n.8, p.1-15, 2004.

MALHEIRO, D.M. Sôbre a ocorrência de Otocentor nitens (Neumann, 1897) Cooley, 1938, Acari - Ixodoidea Ixodidae, em cavalos dos Estados de São Paulo, Minas Gerais e Mato Grosso, Brasil. Revista da Faculdade de Medicina Veterinária de São Paulo, v.4, n.4, p.533-535, 1952.

OLIVEIRA, P.R. Controle estratégico do Boophilus microplus (Canestrini, 1887) em bovinos de propriedades rurais dos municípios de Lavras e Entre Rio de Minas - Minas Gerais. 1993. 97f. Dissertação (Mestrado em Medicina Veterinária) - Escola de Veterinária da Universidade Federal de Minas Gerais, Belo Horizonte, 1993.

ROBY, T.O.; ANTHONY, D.W. Transmission of equine piroplasmosis by Dermacentor nitens Neumann. Journal
American Veterinary Medical Association, v.142, n.2, p.768-769, 1963.

SANAVRIA, A.; PRATA, M.C.A. Ensaio metodológico para estudo do ciclo biológico do Anocentor nitens (Neumann, 1897) (Acari: Ixodidae) em eqüinos experimentalmente infestados. Revista Brasileira de Parasitologia Veterinária, v.5, n.2, p.91-93, 1996.

SAMPAIO, I.B.M. Estatística aplicada à experimentação animal. Belo Horizonte: Fundação de Estudo e Pesquisa em Medicina Veterinária e Zootecnia, 2002. 265p.

SOUZA, A.P.; SERRA-FREIRE, N.M. Variação sazonal dos estádios adultos de Amblyomma cajennense e Anocentor nitens, como parasitas de cavalos no município de Itaguaí, RJ, Brasil. Revista Brasileira de Parasitologia Veterinária, v.1, n.1, p.31-34, 1992.

SOUZA, A.P.; SERRA-FREIRE, N.M. Variação sazonal da fase não parasitária de Amblyomma cajennense e Anocentor nitens no município de Itaguaí, RJ: Avaliação epidemiológica e metodológica. Revista da Universidade Rural: Série Ciências da vida, v.16, n.1-2, p.67-74, 1994.

Recebido em 21 de maio de 2007.

Aceito para publicação em 17 de outubro de 2007. 